\title{
Fragmentos de uma fraude: o caso Binjamin Wilkomirski*
}

Fragments of a fraud: the case of Binjamin Wilkomirski

Pollyanna Gomes dos Santos**

Resumo: A partir da diferenciação entre plágio, fraude e estratégia ficcional, objetiva-se, neste ensaio, analisar a construção de textos literários que tenham uma possível conotação entre escrita e crime. Como afirma Anatol Rosenfeld, a fraude literária é tão antiga quanto a própria literatura. Um dos títulos escolhidos para esta pesquisa é Fragmentos: memórias de uma infância 1939-1948, de Binjamin Wilkomirski. No livro, o autor-narrador relata que foi prisioneiro de campos de concentração e sobrevivente da Segunda Guerra Mundial. Após o enorme sucesso que o livro alcançou e apreciações positivas por parte de críticos literários em todo o mundo, descobriu-se, enfim, que sua história não era verdadeira.

Palavras-chave: Fraude. Testemunho. Shoah.

Abstract: Taking into account the difference between plagiarism, fraud and fictional strategy, the main goal of this essay is to analyze the construction of literary texts that have a possible connotation between writing and crime. As stated by Anatol Rosenfeld, the literary fraud is as old as literature itself. One of the books chosen for this research is Fragments: Memories of a Wartime Childhood, written by Binjamin Wilkomirski. In the book, the author, who is also the narrator, affirms he was a prisoner of internment camps and a survivor of the Second World War. After a great success that the book reached and positive assessments by critics over the world, it was discovered that his history was not true.

Keywords: Fraud. Testimonial. Shoah.

\section{0 crime, a lei e a literatura}

O crime, o mal transgressor às leis, devidamente arquitetado; o detetive, observador distante, disposto a desvendar um segredo e, assim, restabelecer a ordem; uma narrativa articulada, permeada por inquietação e suspense, que transita entre a investigação e a elucidação do enigma. Esses elementos, combinados, estruturam a chamada literatura policial no Ocidente. Há, ainda, um leitor de olhar ansioso, desconfiado, que junto ao detetive, e/ou ao narrador, decide entrar neste labirinto, e com ele, desvendar o mistério que mantém viva a narrativa.

Historicamente, o precursor do gênero policial é Edgar Allan Poe (1809-1849). Poeta, contista e crítico literário norte-americano, é considerado o "escritor que revolucionou a arte de escrever contos, histórias de detetive, ficção científica e fantástica, poesia lírica e histórias de terror" (JEHA \& NASCIMENTO, 2009). A ele é atribuído não só a fundação do gênero policial, mas também a criação da palavra detective, que não existia em inglês até a escrita de Poe. ${ }^{1} \mathrm{O}$ conto The murders in the Rue Morgue publicado em 1841, na Graham's Magazine, é tido como o marco literário do gênero policial. Nele, aparece o primeiro detetive da história: Chevalier Auguste Dupin, descrito pelo narrador como um homem perspicaz, lógico e excêntrico ${ }^{2}$ responsável por investigar crimes brutais em Paris. Porém, a sua forma de investigação diverge dos métodos convencionais, tal qual é conhecida nos dias de hoje. Diferentemente da polícia, ele está sempre distante, observando, explorando novas formas de solucionar crimes. Dupin é um detetive amador e suas buscas ocorrem de maneira paralela.

O detetive amador de Poe, Auguste Dupin, acabou por inspirar a criação de outros investigadores bastante conhecidos: Sherlock Holmes, de Arthur Conan Dayle (1859-1930) e Hercule Poirot, de Agatha Christie (1890-1976), compõem uma galeria de mestres da investigação na literatura. No 
entanto, esses detetives se diferenciam de Dupin quanto à maneira de análise. Sherlock Holmes ficou conhecido por utilizar o método científico e a lógica dedutiva; Hercule Poirot valia-se mais do trabalho de dedução mental que dos métodos empíricos.

Em todas essas histórias, como observaram JEHA \& NASCIMENTO (2009), "testemunhas, réus confessos, vítimas, criminosos e vingadores habitam páginas e páginas da literatura promovendo, entre o crime e a lei, inúmeras possibilidades de escrita e de leitura". ${ }^{3} \mathrm{O}$ leitor desse tipo de narrativa, ansioso por uma resolução, transita pela cena do crime, pela mente dos personagens, pelos fatos. Por meio da leitura, chave de acesso ao criptografado, ao obscuro, o leitor participa do texto, estudando-o, avaliando suas estratégias de enunciação. ${ }^{4}$ Assim, no âmbito da literatura policial, o enigma encoberto pelo criminoso necessita de um detetive que desvende o mistério. O leitor assume, então, o papel importante de investigador, caminhando lado a lado ao narrador/detetive, pois tem o poder de trazer à compreensão aquilo que está oculto. ${ }^{5} \mathrm{Na}$ encenação revelada pela literatura, entrelaçam-se o crime, a lei e a linguagem. O enigma é a força impulsora da narrativa. Uma vez esclarecido, a narrativa encerra-se.

\section{O crime literário: outra face}

Além do crime retratado na ficção, com seus elementos próprios como o detetive e o enigma que deve ser desvendado, a literatura pode vir a se constituir como um crime. De acordo com Jeha, entende-se por crime toda ação essencialmente malévola, na qual há "intenção e consciência do agente", 6 ou seja, há um "desvio intencional da ordem moral".7 O plágio, a fraude e os escritos apócrifos trabalhariam, então, nessa outra órbita, a da literatura enquanto delito. Nas palavras de Anatol Rosenfeld, "a fraude [literária] é quase tão antiga quanto a própria escrita".8

Uma das práticas mais comuns de embuste é o plágio, isto é, a apropriação indevida da obra de outro criador, assumindo-se como se fosse de própria autoria. O plágio é caracterizado pela pilhagem do trabalho de outrem: "Plagiar é copiar no substancial obras alheias dando-as como próprias". $9 \mathrm{Na}$ contramão do plágio, estaria, para Rosenfeld, a fraude, ou seja, "a atribuição a outrem um trabalho de própria autoria". ${ }^{10}$ Nesse caso, o escritor associa à obra o nome de terceiros ou cria autores fictícios com o intuito de aumentar o prestígio do próprio trabalho. De maneira geral, o objetivo é político ou financeiro. Além do plágio e da fraude, outra modalidade de textos de duvidosa legitimidade é a dos escritos apócrifos, que recentemente, têm ganhado espaço no mercado literário. Segundo Nascimento, os apócrifos são aquelas "obras ou fatos sem autenticidade, ou cuja autenticidade não se provou" e ainda, os textos que não foram incluídos em determinado cânone.

Fragmentos: memórias de infância 1939-1948, de Binjamin Wilkomirski, ${ }^{11}$ parece configurar-se como um desses textos, pois para muitos estudiosos ainda existem dúvidas quanto à sua autenticidade e o valor literário ou jurídico da história. No livro, o autor, e também narrador, retomaria as memórias de sua primeira infância, incluindo-se aí as poucas lembranças de membros da família, a rotina nos campos de concentração de Majdanek e Auschwitz, na Polônia, o orfanato para onde foi levado durante a guerra, a vida em família após a adoção e algumas das impressões de si na maturidade. Por quase três anos, essa narrativa teve grande aceitação de público e crítica e foi considerado um dos mais impressionantes relatos da barbárie nazista.

Todavia, a história narrada por Wilkomirski tornou-se alvo de um escândalo, depois que reportagens foram publicadas no jornal suíço Weltwoche, em 1998. Após a consagração do livro, um jornalista suíço, não convencido da autenticidade da narrativa de Wilkomirski, começa então a investigar a história de vida do autor e, tal como um detetive, teria desvendado o mistério. De acordo com seu relato em inúmeras reportagens que publica sobre o caso, as memórias de infância e do Holocausto 
narradas por Wilkomirski em Fragmentos: memórias de infância 1939-1948 são, na verdade, uma obra ficcional.

\section{Fragmentos, de Binjamin Wilkomirski: uma fraude literária?}

Publicado em 1995, na Suíça, pela editora alemã Suhrkamp e traduzido para mais de doze línguas, o livro foi ainda adaptado, segundo Márcio Seligmann-Silva, para o teatro e o cinema. ${ }^{12}$ Desde a publicação, o autor foi convidado inúmeras vezes para testemunhar em escolas e universidades, dentro e fora da Europa. Considerado pela crítica, num primeiro momento, um dos exemplos de maior expressão da literatura de testemunho, Fragmentos tornou-se uma referência nos Holocaust Studies e recebeu importantes prêmios, tais como o National Jewish Book Award (Nova Iorque) e o Memória da Shoah ${ }^{13}$ (Paris), recebidos antes por nomes como Elie Wiesel e Alfred Kazin.

Com características de uma autobiografia, Fragmentos descreve a trajetória de Binjamin Wilkomirski, um garoto entre três e sete anos de idade, ${ }^{14}$ desde as primeiras lembranças na Polônia, até sua adoção por uma rica família na Suíça. Em seus relatos, o narrador retrata a morte de um homem que acredita ser seu pai, revela a admiração pelo irmão mais velho Mordechai e pela amiga Karola, rememora os sofrimentos e privações nos barracões dos campos de concentração, a sensação de estranhamento quando da chegada ao orfanato, a nova vida na Suíça após a adoção pelo casal de médicos, entre outros episódios. Como sugere o título, a narrativa apresenta-se fragmentada, na qual pouco se sabe sobre a família do narrador, os locais por onde teria passado, as pessoas que, talvez, tenham cruzado o seu caminho. No texto, Wilkomirski, ao longo de seus relatos, assume a dificuldade de reproduzir os fatos, dada a distância em relação ao seu passado e a dor de tais recordações, como demonstram os trechos a seguir:

As lembranças mais antigas que trago comigo assemelham-se a um campo em ruínas de imagens e acontecimentos isolados. (...) Estilhaços de memória dotados de contornos duros e afiados feito faca, ainda hoje capazes de ferir, se tocados. Na maioria das vezes, esparsos e caóticos, apenas raramente organizáveis numa ordem cronológica; estilhaços que seguem sempre opondo-se de forma obstinada ao desejo de ordená-los daquele que se fez adulto, e que escapam às leis da lógicas. ${ }^{15}$

Não me lembro como tudo terminou. ${ }^{16}$

Minha memória preservou apenas o final da viagem, e mesmo cheio de lacunas, confusão, imagens fragmentadas, muitos pedaços faltando. ${ }^{17}$

Embora escrito numa linguagem simples, mas com um vocabulário refinado, os relatos de Wilkomirski surpreendem pela crueza das palavras. No capítulo "As ratazanas", por exemplo, o narrador retrata a profana rotina do campo onde teria sido prisioneiro:

De repente, há muitas mulheres ali, mulheres que morrem à noite, e então outras, novas mulheres chegam, e estas morrem também. Toda manhã, as mortas são jogadas na esquina de cada barraca por aquelas que vão morrer na noite seguinte. (...) E, toda manhã, vem a carroça puxada por pessoas cinza e esfarrapadas (...). Elas jogam as mulheres mortas dentro da carroça e seguem adiante. ${ }^{18}$

Mais adiante, no mesmo capítulo, está um dos trechos mais dramáticos da obra: 
Agora posso ver de barriga inteira: de um dos lados, dentro de uma grande ferida, alguma coisa está se mexendo. Eu me ergo para poder ver melhor. Estico a cabeça para a frente e, nesse momento, a ferida se abre de repente, a parede do abdome se levanta e uma enorme ratazana, brilhante e lambuzada de sangue, escorrega pela montanha de corpos até o chão. Assustadas, outras ratazanas disparam daquela confusão de corpos, fugindo para longe. ${ }^{19}$

Seligmann-Silva, no artigo "Os fragmentos de uma farsa",20 cunha o termo "obra testemunhal" para referir-se à narrativa de Wilkomirski. A escolha do termo está ligada ao fato de o livro de Wilkomirski tratar-se, para o crítico, de uma memória simulada, ou seja, uma narrativa ficcional. Portanto, não se enquadraria na chamada Literatura de Testemunho, segundo a perspectiva judaica.

O leitor pode, diante do texto de Wilkomirski, perceber um esforço do narrador, que sob a perspectiva de uma criança, tenta costurar as duras e fragmentadas lembranças, diante do horror da guerra. ${ }^{21} \mathrm{Nas}$ páginas finais do livro, o autor-narrador esclarece ainda, que escreveu suas memórias como forma de investigar a si mesmo e ao seu passado, e com o intuito de se libertar, no sentido de fazer emergir, tudo aquilo que, segundo ele, foi censurado ao longo dos anos. "Eu cresci", afirma, "e me tornei adulto numa época e numa sociedade que não queria ou não podia me ouvir".22 Para o narrador, escrever era a única maneira de não se calar, e assim, não ter suas memórias apagadas. "É, afinal, muito fácil mergulhar em incerteza as lembranças de uma criança, fazê-la calar. Eu queria minha certeza de volta, e não queria mais calar. Por isso, comecei a escrever".23

O texto de Wilkomirski reuniria, portanto, características comuns a de outros relatos da Shoah, principalmente porque tenta, por meio da linguagem, dar forma a uma experiência traumática. Para Seligmann-Silva, o testemunho representa a articulação "entre a necessidade de narrar a experiência da barbárie e a percepção da insuficiência da linguagem diante do horror". ${ }^{24}$ Dessa forma, ao tentar traduzir o inenarrável, ${ }^{25} \mathrm{o}$ escritor procede tal como fazem muitos sobreviventes, os quais para aliviarem o peso da memória traumática, têm a necessidade de relatar os acontecimentos do passado. Logo, o testemunho pode ser entendido não só na acepção jurídica da palavra, como também "no sentido de 'sobreviver', de ter-se passado por um evento-limite, radical, passagem essa que foi também um 'atravessar' a 'morte', que problematiza a relação entre a linguagem e o 'real'". Nesse sentido, o testemunho cumpriria, então, um papel fundamental na vida do indivíduo traumatizado, funcionando, portanto, como uma válvula de escape.

Mais que uma obra de rara perspectiva, isto é, que parte do ponto de vista de uma criança, a narrativa destacou-se entre tantas outras, pela desmedida realidade descrita. Fato este que contribuiu para sua ampla repercussão, já que nenhum testemunho abarcava tantos detalhes, ${ }^{26}$ nem se apresentava sob a ótica infantil, desde $O$ diário de Anne Frank:

Era uma espécie de obra única, porque mesmo o escrito de Anne Frank era um diário, portanto, um outro gênero. O livro de Wilkomirski colocava-se como uma espécie de memorial testemunhal escrito muitas décadas depois da Segunda Guerra Mundial por um adulto que estaria tentando reconstruir aqueles fragmentos de memória. (...) O fato de ele ter se colocado do ponto de vista de uma criança era muito impactante..$^{27}$

A combinação de elementos como a linguagem em primeira pessoa, a referência a cidades reais, a descrição dos campos e de sua rotina, e, principalmente, o fato de o autor-narrador ter se apresentado como autêntico sobrevivente, contribuiu para que a sua narrativa fosse vista como um relato verídico. Entretanto, o jornalista e escritor Daniel Ganzfried, incrédulo dos fatos, decidiu investigar o caso e, 
entre 27 de agosto e 3 de setembro de 1998, publicou reportagens revelando o que seria a verdadeira identidade de Wilkomirski.

Após três anos do lançamento de Fragmentos, descobriu-se que a obra se tratava de uma "memória ficcional", isto é, uma história simulada, que cria e reinterpreta fatos, e que Binjamin Wilkomirski chama-se, na verdade, Bruno Doessekker.

Segundo dados levantados pelo jornalista, Doessekker, não é judeu nem tampouco de origem judaica. A reportagem revela, ainda, que o escritor, músico e construtor de instrumentos musicais, estudou história em Genebra e possui em casa, um grande acervo de livros sobre a Segunda Guerra Mundial. Além disso, ele conheceu os Campos de Concentração apenas como turista e pesquisador. Ainda, de acordo com Ganzfried, ele se chamava, antes de ser entregue à adoção, Bruno Grosjean. A família que o acolheu conseguiu alterar o sobrenome antes que ele começasse sua vida escolar. A série de reportagens de Ganzfried divulgou, também, que sua mãe biológica faleceu em 1981 e seus pais adotivos, em 1985.

Mas por que uma obra apresentada como sendo a "autobiografia de um sobrevivente de campos de concentração" foi posta em xeque pelo jornalista? De fato, ao se examinar o texto de Wilkomirski, o leitor pode duvidar da autenticidade da história, quando o narrador fala, por exemplo, sobre a sua data de nascimento: "O documento, que tenho agora nas mãos - (...) um atestado provisório -, traz como minha data de nascimento 12 de fevereiro de 1941."28 E acrescenta: "Essa data, porém, não coincide com a história de minha vida ou com minhas lembranças. Tomei medidas legais contra essa identidade decretada. A verdade juridicamente atestada é uma coisa; a verdade de uma vida é outra". ${ }^{29} \mathrm{O}$ que justamente intrigou o jornalista era a possibilidade de haver "duas verdades". Qual poderia ser o real objetivo de Wilkomirski? Teria sido a obra escrita com intuito financeiro ou o autor sofre de algum transtorno psiquiátrico? De quem é a voz do narrador? Teriam sido esses fatos relatados por outros sobreviventes?

Até que ponto a obra de Wilkomirski pode ser considerada testemunho? A narrativa que tenta dar conta do intraduzível, do inenarrável ${ }^{30}$ poderia ser chamada de ficção? O que se percebe é que Wilkomirski parece ter conseguido extrapolar a fronteira entre o real e o ficcional, no qual o primeiro tornou-se matéria-prima para o segundo. Contudo, a tentativa de recriar a cena do horror por meio de palavras quase sempre insuficientes, acabou rompendo com a ética da representação que reside sobre o testemunho judaico, uma vez que Fragmentos, ao não se deixar definir se é uma história forjada, simulada por alguém que nunca conheceu os Campos de Concentração, na condição mesma de prisioneiro, um testemunho ou se é, apenas ficção. Mais que isso, trata-se de um texto que se apresentou ao mundo como verdadeiro, seu autor como um sobrevivente, mas mesmo se provando ser esta uma mentira, será que o seu texto pode ser considerado uma fraude? Porque, se para alguns estudiosos da literatura, a atitude de Wilkomirski fere os princípios éticos do testemunho, à luz da psicanálise, essa escrita fraudulenta do sujeito pode ser um desdobramento da condição de testemunha, qual seja a de identificação de um sujeito, que não passou por aquele trauma, mas que com ele se identifica a ponto de nele se perder.

Na perspectiva judaica, a memória é preservada não somente por meio dos rituais, como por exemplo, a Festa de Purim, na qual é celebrada a salvação dos judeus na Pérsia, por Esther, mas também no testemunho de quem sobreviveu à Shoah, como é o caso de Primo Levi:

Nós, tocados pela sorte, tentamos narrar com maior ou menor sabedoria não só nosso destino, mas também aquele dos outros, dos que submergiram: mas tem sido um discurso 'em nome de terceiros', a narração de coisas vistas de perto, não experimentadas pessoalmente. (LEVI, p. 47) 
Diante do exposto, pode-se dizer que a escrita de Wilkomirski choca-se de certa forma com o compromisso ético judaico, não por sua tentativa de narrar as lembranças do passado, mantendo-se assim, a tradição de recordar e contar, mas, por fazê-lo assumindo uma falsa identidade, que deixa escapar, ainda, entre essas possibilidades, a de uma simulação clínica, psicológica. Em outras palavras, o narrador cria uma voz de alguém que nunca existiu, trazendo à tona uma memória ficcional, resultado de um trabalho de experimentação e reencenação das palavras. Trata-se, portanto, de uma questão moral, visto que Wilkomirski parece apresentar-se de má-fé, ao se dar ao mundo como autêntico sobrevivente. Se aceito esse prisma, pode-se dizer que Wilkomirski transita entre a lucidez e a loucura, uma vez que sua escrita demonstra o conhecimento científico do autor, influenciada por fatos históricos e pela cultura. Em sua narrativa, ele se apropria da memória coletiva da Shoah, assimila-a e a transforma em memória individual, simulando-a, reencenando e reinterpretando a história a sua maneira.

\section{A narrativa contemporânea}

No ensaio $O$ narrador, Walter Benjamin afirmou o fim da experiência transmissível e, também, das grandes narrativas da tradição. Para ele, a arte de narrar estava com os dias contados por dois motivos: porque as pessoas já não sabiam mais como fazê-lo e porque o advento da Primeira Guerra Mundial acabou por emudecer os sobreviventes, que, diante do choque causado pelo conflito, tornaram-se incapazes de relatar suas experiências. ${ }^{31}$ Porém, Benjamin equivoca-se ao decretar a extinção do relato em função da escassez de testemunhos, "justamente porque 'a guerra de 1914-8 marca o começo do testemunho de massas'."32 Os acontecimentos do início do século 20 significaram um divisor de águas na história contemporânea, provocando mudanças radicais. Diferentemente do que acreditava Benjamin, a crise estabelecida a partir de então, possibilitou ou exigiu o desenvolvimento de novas formas narrativas.

A Literatura de Testemunho e os relatos autobiográficos configuram-se como reflexos desse novo panorama literário. Portanto, a mesma humanidade que assiste aos acontecimentos bárbaros de sua história, reflete sobre a dimensão de sua decadência. As grandes transformações ocorridas desde o início do século 20 acabaram por iluminar a tradição literária, permitindo novas possibilidades de narração. Uma delas é o testemunho, cuja estrutura narrativa seria sempre incompleta, constituída de retalhos. Por isso mesmo, passível de ser inventada, reordenada, reinterpretada, e, em alguns casos, forjada.

Tem-se assim, uma narrativa híbrida que incorpora certezas e dúvidas, como é o caso do relato de Fragmentos: memórias de infância 1939-1948. O que parece estar em evidência, porém, no texto de Wilkomirski é essa possibilidade de narrar a partir da ideia de "literatura forjada". O verbo "forjar", segundo o Dicionário Aurélio da Língua Portuguesa, aponta para essa ambigüidade: pode significar fabricar, fazer, no sentido de criar ou compor, e ainda, falsificar, arquitetar, maquinar, ou seja, dissimular. Os vários significados do verbo convergem para o fato de que a história é fruto do imaginário do autor. A diferença, porém, é que, no que se refere à ética, o leitor deve estar ciente de que tem nas mãos uma história ficcional. No caso de Wilkomirski, até a publicação das reportagens por Ganzfried, o público leitor não tinha conhecimento de que os relatos de Wilkomirski seriam forjados, isto é, que não eram autênticos ou verdadeiros. Entretanto, apesar de todas as provas que Ganzfried levantou sobre o que se poderia chamar de real no relato de Wilkomirski, ainda restam dúvidas se o seu texto é uma forja ficcional ou criminosa.

\section{Fragmentos e suas estratégias de enunciação}

Em linhas gerais, o narrador de Fragmentos esforça-se para reconstruir, forjar, sua história pessoal e familiar e ainda, recriar os cenários dos locais por onde passou e viveu, a partir de fraturadas 
lembranças. Embora a narrativa não siga uma ordem cronológica, a história possui, de alguma maneira, arranjo lógico. Não há menção de datas, tampouco os fatos são contados na seqüência em que ocorreram, entretanto, a história tem início na Polônia, cujas primeiras lembranças remetem à família, tais como a morte do pai e a separação dos irmãos, recria a rotina nos campos paralela à vida no orfanato e encerra-se na Suíça, após a adoção pela família Doessekker.

Apesar das lacunas presentes no relato, pode-se dizer que a narrativa de Wilkomirski demonstra precisão, habilidade e envolvimento do narrador, tão caros ao sobrevivente, ao tentar dar conta do intraduzível. Fragmentos, portanto, reuniria três das cinco características listadas por Italo Calvino, em Seis propostas para o novo milênio, como valores a serem preservados pela literatura na contemporaneidade: exatidão, visibilidade e multiplicidade. Tais características acabam por reforçar o estatuto ficcional do texto.

Para Calvino, a exatidão na literatura aparece como"um projeto bem definido e calculado", capaz de evocar imagens nítidas e memoráveis, cuja linguagem seja "a mais precisa possível (...) em sua capacidade de traduzir nuanças do pensamento e da imaginação". ${ }^{33} \mathrm{O}$ trecho a seguir, de Fragmentos, parece ilustrar essa característica:

O homem, eles encostaram à parede do edifício, ao lado do portão de entrada. Aos berros, os uniformizados saltam rumo a um veículo parado na rua; jogam os braços para cima, brandem bastões e retorcem seus rostos em raivosa fúria. E seguem gritando sempre o mesmo, algo como: 'Acabem com ele! Acabem com ele!' O veículo põe-se em movimento. Avança cada vez mais rápido em direção à parede do edifício, rumo a nós. (...) De repente, porém, seu rosto se desfigura, ele se volta para o outro lado, ergue a cabeça e escancara a boca, como se fosse gritar. (...) Da garganta não lhe sai grito algum, mas um poderoso jorro negro lança-se de seu pescoço quando crepitando, o veículo o esmaga contra a parede do edifício. ${ }^{34}$

Nesse trecho, o narrador consegue descrever em poucas palavras, a morte do homem que se supõe ser seu pai. A linguagem simples, a seqüência em detalhes de imagens, bem como a precisão dos fatos ajuda o leitor a imaginar a cena, na qual o pai do narrador é morto esmagado contra uma parede.

Outro valor literário considerado por Calvino, diz respeito à visibilidade. Para o crítico, o poeta, ao elaborar seu trabalho, deve imaginar visualmente não só aquilo que seu personagem vê, mas também deve conceber o "conteúdo visual das metáforas de que se serve precisamente para facilitar essa vocação visiva", 35 como fez Dante, em Divina Comédia. Ou seja, é necessário projetar interiormente uma sucessão de imagens que serão descritas na obra. A partir dessas considerações, Calvino postula que há dois tipos de processos imaginativos: aquele que parte da palavra para chegar à imagem e o que parte da imagem e consegue ser expresso verbalmente. No capítulo "A casinha do cachorro", do livro de Wilkomirski, é possível ver delinear-se essa característica:

Mas o mais nojento eram uns besouros gordos, duros e triangulares, zunindo em direção a minha cabeça e enfiando-se por minhas roupas. Procurei proteger ao menos as mãos, metendo-as no bolso semicircular de meu bibe. Também no bolso, porém, encontrei besouros, e, semi-esmagados, eles exalavam um cheiro horrível. ${ }^{36}$

É possível perceber, na citação, as palavras que demonstram o poder de descrição do narrador. A riqueza de detalhes ajuda o leitor a recriar imaginariamente a cena, com base nas características do relato. Nele, o narrador descreve a forma dos insetos que o perturbavam, e ainda, discorre sobre a sensação de repulsa e até do cheiro exalado pelos besouros. Assim, o leitor é capaz de projetar a cena por ele descrita, não só pelo uso de adjetivos, mas também pelas impressões do autor-narrador. 
A terceira característica de fundamental importância para a literatura, conforme postula Calvino, é a multiplicidade. Um texto multíplice é, para o crítico, aquele que se assemelha a uma enciclopédia, isto é, que estabelece uma rede de conexões entre "fatos, pessoas e as coisas do mundo". ${ }^{37}$ Além disso, significa uma obra polifônica, capaz de reunir "sujeitos, vozes, olhares sobre o mundo". 38 Mesmo assim, o escritor teria seus planos frustados, ao tentar dar conta do todo, com sua desmedida ambição. $\mathrm{O}$ trecho de Wilkomirski, a seguir, configura-se como um bom exemplo:

\begin{abstract}
A blockowa - ou teria sido a lagerserka? - passou apressada por mim, suas botas duras e altas espirrando lama no meu rosto. Não tem importância, ela sempre faz isso. Afinal, nós, crianças, somos lixo de qualquer jeito, é o que ela sempre diz, e, portanto, não faz diferença. Estou, pois, sentado ali, e, como não há outras crianças, sigo brincando na lama. (...) De vez em quando, olho para as mulheres mortas. Crianças mais velhas contaram que as criancinhas crescem na barriga das mulheres antes de nascer, e eu fico pensando: todos sempre dizem que sou pequeno. Isso só pode significar que também cresci numa barriga assim. Penso em minha mãe, e naquela única vez que o uniforme cinza me levou até uma mulher e disse: 'Você vai poder ver sua mãe'.39
\end{abstract}

Nesse trecho, o narrador mescla sua voz e pensamentos com a voz de outras crianças e adultos. Ele também estabelece relação entre a soldado nazista e seu comportamento, demonstrando seu conhecimento sobre a hierarquia presente no campo. Ainda, levanta suposições acerca da sua origem e da sua mãe. Contudo, o narrador se encontra cercado de dúvidas, sem respostas, para seu constante questionamento interior.

Pode-se dizer, portanto, que Wilkomirski consegue com êxito, fazer com o leitor imagine as cenas por ele recriadas, a partir de seus relatos. Ainda que sua narrativa possua lacunas e não siga nenhuma ordem cronológica, como alguns textos de testemunhos se apresentam, a descrição detalhada dos fatos permite ao leitor recriar as imagens e, ao mesmo tempo, chocar-se com as cenas do horror ali inscritas. Graças à narrativa de Fragmentos, Wilkomirski tornou-se conhecido em vários países, sendo sua obra considerada um dos mais impressionantes relatos da Shoah - até que fossem publicadas as reportagens que o desmentiram. A partir desse fato, a questão que se coloca é o incômodo gerado pela descoberta da fraude, isto é, do falso relato, da construção da identidade de Binjamin Wilkomirski. Por outro lado, e se a farsa não tivesse sido descoberta? Ainda seria atribuída a obra, o valor de importante testemunho. Ademais, o livro teria recebido a mesma apreciação se soubesse se tratar de uma obra ficcional? Afinal de contas, Fragmentos pode ser enquadrado como testemunho ou ficção? Apesar dos incansáveis esforços que tentam responder a essas e outras perguntas, muitas continuarão incógnitas para o leitor, bem como para os pesquisadores e críticos do livro de Wilkomirski.

Ainda assim, longe de esgotar as discussões sobre os relatos de Fragmentos, pode-se, no entanto, avaliar o texto ou a atitude de Wilkomirski sob duas perspectivas diferentes: à luz da Literatura e da Psicanálise. Sob o ponto de vista literário, não se levando em conta a autenticidade do relato, tem-se uma espécie de testemunho ficcionalizado, uma vez que o autor-narrador se apresentou como autêntico sobrevivente da Shoah. Para isso, ele criou uma persona, isto é, uma máscara, um personagem e forjou um relato. Tem-se, dessa maneira, a forja da ficção. Para a Psicanálise, essa escrita fraudulenta pode significar uma espécie de identificação com o Outro, ou seja, com aquele que sofreu a experiência traumática da quase-morte. Mesmo não tendo passado pela experiência dolorosa dos campos, Wilkomirski conseguiu transpor para o papel, aquilo o que para muitos sobreviventes é custoso ou impossível de realizar: o testemunho da barbárie. Apesar de não ser factual, seu relato se configura como denúncia do horror e, de certa forma, parece fazer justiça aqueles que foram silenciados pela morte. 
No entanto, ao passar-se por sobrevivente, acaba por se estabelecer, a forja do crime. O psicanalista José Francisco B. Santos afirma:

Não há valor jurídico no testemunho do livro de Wilkomirski. Toda obra literária é, antes de tudo, um testemunho do autor. Um escrito literário testemunhal não é, necessariamente, um documento jurídico, logo, o que temos aí é um texto literário e, como tal, é sob a referência da estética que deve ser julgado. 40

Finalmente, para além das questões éticas e estéticas que envolvem o texto de Wilkomirski, é pertinente retomar a ideia inicial deste artigo, sobre literatura policial e sua possível relação com Fragmentos. Embora não haja um enigma que mantenha viva a narrativa, dado os acontecimentos relatados no livro e também, as circunstâncias históricas, persiste a figura do detetive: tanto Wilkomirski quanto o jornalista Daniel Ganzfried, responsável por revelar o falso testemunho, constituem-se como investigadores. Seja pela construção da narrativa, que ganha vida nas palavras do autor-narrador, seja na desconstrução da história, pelo repórter que se empenhou em provar que a história de Wilkomriski não era verdadeira.

De acordo com Seligmann-Silva: "O nosso século se identifica e será identificado com Auschivitz. Se a 'realidade' descrita por Wilkomirski/Doesseker é terrível e insuportável, a dos campos de concentração era muito pior. As crianças pequenas não tiveram a sorte de saírem vivas". ${ }^{41}$ Tudo isso posto, é coerente dizer que o texto de Wilkomirski consegue ir além dos limites entre o ficcional e o factual, na medida em que instaura uma dúvida que permanecerá até se se houver uma confissão de fraude. Se por um lado, o relato do autor-narrador assemelha-se a um autêntico testemunho da Shoah, por outro, apesar das críticas e discussões em torno do livro, a descoberta da farsa não diminui o apelo ficcional da narrativa. O crime permanece, portanto, entre fato e fábula, em suspenso, a espera de leituras do porvir.

* Pollyanna Gomes dos Santos é graduanda em Letras na Faculdade de Letras da UFMG e bolsista de Iniciação Científica do CNPq.

\section{Notas}

${ }^{1}$ SPARKNOTES EDITORS. SparkNote on Poe's Short Stories. SparkNotes LLC. 2002. Disponível em: http://www.sparknotes.com/lit/poestories/. Acessado em 22 mar. 2010.

${ }^{2}$ ELLIOT, E.; KERBER, L.; LITZ, A.; MARTIN, T. Edgar Allan Poe. In: American literature: a Prentice Hall anthology. New Jersey, 1991.

3JEHA, Júlio; NASCIMENTO, Lyslei. Crimes, pecados e monstruosidades. In: JEHA, Júlio; NASCIMENTO, Lyslei (Org.). Suplemento Literário. Belo Horizonte, 2009. Edição especial.

${ }^{4}$ NASCIMENTO, Lyslei. Borges e outros rabinos. Belo Horizonte: Editora UFMG, 2009.

${ }^{5}$ NASCIMENTO, 2009, p. 159.

${ }^{6} \mathrm{JEHA}$, Júlio (Org.). Monstros e monstruosidades na literatura. Belo Horizonte: Editora UFMG, 2007 apud LARANJEIRA, Delzi Alves. Judas: da tradição à traição como literatura. In: JEHA, Júlio; NASCIMENTO, Lyslei (Org.). Suplemento literário. Belo Horizonte, 2009. Especial Monstros.

${ }^{7}$ JEHA, Júlio (Org.). Monstros e monstruosidades na literatura. Belo Horizonte: Editora UFMG, 2007.

${ }^{8}$ ROSENFELD, Anatol. Mistificações literárias: "Os protocolos dos sábios de Sião". São Paulo: Perspectiva, 1982.

${ }^{9}$ FRIEIRO, Eduardo. Falando de plágios. In: Torre de papel: motivos literários. Belo Horizonte: Imprensa, 1969. 
${ }^{10}$ FRIEIRO, 1969, p. 215.

${ }^{11}$ WILKOMIRSKI, Binjamin. Fragmentos: memórias de infância 1939-1948. Trad. Sérgio Tellaroli. São Paulo: Companhia das Letras, 1998.

${ }^{12}$ SELIGMANN-SILVA, Márcio (Org.). História, memória, literatura: o Testemunho na Era das Catástrofes. Campinas: Editora da UNICAMP, 1999.

${ }^{13}$ Segundo Seligmann-Silva (1999, p. 43), Shoah é o termo academicamente e politicamente correto para indicar o assassinato de seis milhões de judeus pelos nazistas.

${ }^{14}$ SELIGMANN-SILVA, 1999, p. 60.

${ }_{15}$ WILKOMIRSKI, 1998, p. 9.

${ }^{16}$ WILKOMIRSKI, 1998, p. 27.

17 WILKOMIRSKI, 1998, p. 122.

${ }^{18}$ WILKOMIRSKI, 1998, p. 115-6.

${ }_{19}$ WILKOMIRSKI, 1998, p. 118.

20 SELIGMANN-SILVA, 1999, p. 60.

${ }^{21}$ SELIGMANN-SILVA, 1999, p. 60.

${ }^{22}$ WILKOMIRSKI, 1998, p. 206.

${ }^{23}$ WILKOMIRSKI, 1998, p. 207.

${ }^{24}$ SELIGMANN-SILVA, 1999, p. 40.

25 SELIGMANN-SILVA, 1999, p. 40.

${ }^{26}$ ARAÚJO, Luciana. O maior impostor do Holocausto. Entrelivros, no 28, p. 40-42, ago. 2007.

27SELIGMANN-SILVA, Márcio apud ARAÚJO, Luciana. O maior impostor do Holocausto. Entrelivros, no 28, p. 40-42, ago. 2007.

${ }^{28}$ WILKOMIRSKI, 1998, p. 208.

${ }^{29}$ WILKOMIRSKI, 1998, p. 208.

${ }^{30}$ SELIGMANN-SILVA, 1999, p. 40.

31 “(...) a experiência de que a arte de narrar está em vias de extinção. São cada vez mais raras as pessoas que sabem narrar devidamente. Quando se pede num grupo que alguém narre alguma coisa, o embaraço se generaliza. É como se estivéssemos privados de uma faculdade que nos parecia segura e inalienável: a faculdade de intercambiar experiências." In: BENJAMIN, Walter. $O$ narrador: considerações sobre a obra de Nikolai Leskov. Magia e técnica, arte e política: ensaios sobre literatura e história da cultura. São Paulo: Brasiliense, 1994.

32 BENJAMIN, 1994, p. 197-221 apud SARLO, Beatriz. Tempo passado: cultura da memória e guinada subjetiva. Trad. Rosa Freire d'Aguiar. São Paulo: Companhia das Letras; Belo Horizonte: UFMG, 2007. ${ }_{33}$ CALVINO, Italo. Seis propostas para o próximo milênio. Trad. Ivo Barroso. São Paulo: Companhia das Letras, 1990, p. 71-72.

${ }^{34}$ WILKOMIRSKI, 1998, p. 12.

${ }_{35}$ CALVINO, 1990, p. 99.

${ }^{36}$ WILKORMIRSKI, 1998, p. 58.

${ }^{37}$ CALVINO, 1990, p. 120.

${ }^{38}$ CALVINO, 1990, p. 120.

39 WILKORMIRSKI, 1998, p. 116.

${ }^{40}$ SANTOS, Francisco José Bezerra. Da verdade (n)o texto. Rio de Janeiro: Escola Letra Freudiana, 2009.

${ }^{41}$ SELIGMANN-SILVA, Márcio. Os fragmentos de uma farsa. In: SELIGMANN-SILVA, Márcio (Org.). A literatura do trauma. Cult, n. 23, junho de 1999.

\section{Referências}

ADORNO, Theodor. Crítica cultural e sociedade. In: . Prismas. Trad. Augustin Wernet e Jorge Mattos Brito de Almeida. São Paulo: Ática, 1998.

AGAMBEN, Giorgio. O que resta de Auschwitz: o arquivo e a testemunha. Trad. Selvino J. Assmann. São Paulo: Boitempo, 2008. 
ARAÚJO, Luciana. O maior impostor do Holocausto. Entrelivros, no 28, p. 40-42, ago. 2007.

ARENDT, Hannah. Eichmann em Jerusalém: um relato sobre a banalidade do mal. Trad. José Rubens Siqueira. São Paulo: Companhia das Letras, 1999.

BENJAMIN, Walter. O narrador: considerações sobre a obra de Nikolai Leskov. Magia e técnica, arte e política: ensaios sobre literatura e história da cultura. São Paulo: Brasiliense, 1994, p. 197-221.

BORGES, Jorge Luis. Kafka e seus precursores. In: Obras completas de Jorge Luis Borges. São Paulo: Globo, 1999, vol. 2.

CALVINO, Italo. Seis propostas para o próximo milênio. Trad. Ivo Barroso. São Paulo: Companhia das Letras, 1990.

ECO, Umberto. Protocolos ficcionais. In: Seis passeios pelo bosque da ficção. Trad. Hildegard Feist. São Paulo: Companhia das Letras, 1994.

ECO, Umberto. Seis passeios pelo bosque da ficção. Trad. Hildegard Feist. São Paulo: Companhia das Letras, 1994.

ELLIOT, E.; KERBER, L.; LITZ, A.; MARTIN, T. Edgar Allan Poe. In: American literature: a Prentice Hall anthology. New Jersey, 1991.

FREUD, Sigmund. Reflexões para os tempos de guerra e morte. In: História do movimento psicanalítico: artigos sobre metapsicologia e outros trabalhos. Trad. Jayme Salomão. Rio de Janeiro: Imago, 1996. (Edição standard brasileira das obras psicológicas de Sigmund Freud, 14).

FRIEIRO, Eduardo. Embustes literários. In: Torre de papel: motivos literários. Belo Horizonte: Imprensa, 1969.

FRIEIRO, Eduardo. Falando de plágios. In: Torre de papel: motivos literários. Belo Horizonte: Imprensa, 1969.

FRIEIRO, Eduardo. Uma fraude literária. In: Torre de papel: motivos literários. Belo Horizonte: Imprensa, 1969.

JEHA, Júlio (Org.). Monstros e monstruosidades na literatura. Belo Horizonte: Editora UFMG, 2007.

JEHA, Júlio; NASCIMENTO, Lyslei. Crimes, pecados e monstruosidades. In: JEHA, Júlio; NASCIMENTO, Lyslei (Org.). Suplemento Literário. Belo Horizonte, 2009. Edição especial.

KUNDERA, Milan. Os testamentos traídos: ensaios. Rio de Janeiro: Nova Fronteira S/A, 1994. LARANJEIRA, Delzi Alves. Judas: da tradição à traição como literatura. In: Suplemento literário. Belo Horizonte, 2009. Especial Monstros.

LEVI, Primo. Os afogados e os sobreviventes. Trad. Luiz Sérgio Henriques. Rio de Janeiro: Paz e Terra, 1990.

LUDMER, Josefina. O corpo do delito: um manual. Trad. Maria Antonieta Pereira. Belo Horizonte: Editora UFMG, 2002.

NASCIMENTO, Lyslei. Borges e outros rabinos. Belo Horizonte: Editora UFMG, 2009.

NAZARIO, Luiz; NASCIMENTO, Lyslei. Os fazedores de golems. Belo Horizonte: Programa de PósGraduação: Estudos Literários, 2004.

NESTROVSKI, Arthur; SELIGMANN-SILVA, Márcio. Apresentação. In: NESTROVSKI, Arthur; SELIGMANN-SILVA, Márcio (Org). Catástrofe e representação. São Paulo: Escuta, 2000.

PURIM. Disponível em: < http://www.morasha.com.br/edicoes/ed39/festa.asp>. Acesso em 05 jun. 2010.

ROSENFELD, Anatol. Mistificações literárias: "Os protocolos dos sábios de Sião". São Paulo: Perspectiva, 1982.

ROSENFIELD, Denis L. Retratos do mal. Rio de Janeiro: Jorge Zahar, 2003.

SANTOS, Francisco José Bezerra. Da verdade (n)o texto. Rio de Janeiro: Escola Letra Freudiana, 2009. Não publicado.

SARLO, Beatriz. Tempo passado: cultura da memória e guinada subjetiva. Trad. Rosa Freire d'Aguiar. São Paulo: Companhia das Letras; Belo Horizonte: UFMG, 2007.

SCHNEIDER, Michel. Ladrões de palavras: ensaios sobre o plágio, a psicanálise e o pensamento. Campinas: Editora da UNICAMP, 1990. 
SELIGMANN-SILVA, Márcio (Org.). História, memória, literatura: o Testemunho na Era das Catástrofes. Campinas: Editora da UNICAMP, 1999.

SELIGMANN-SILVA, Márcio. Reflexões sobre a memória, a história e o esquecimento. In: SELIGMANN-SILVA, Márcio (Org.). História, memória, literatura: o Testemunho na Era das Catástrofes. Campinas: Editora da UNICAMP, 1999.

SELIGMANN-SILVA, Márcio. A literatura do trauma. Cult, n. 23, junho de 1999.

SELIGMANN-SILVA, Márcio. Apresentação da questão. In: SELIGMANN-SILVA, Márcio (Org.). História, memória, literatura: o Testemunho na Era das Catástrofes. Campinas: Editora da UNICAMP, 2003b.

SELIGMANN-SILVA, Márcio. Introdução. In: SELIGMANN-SILVA, Márcio (Org.). História, memória, literatura: o Testemunho na Era das Catástrofes. Campinas: Editora da UNICAMP, 2003.

SELIGMANN-SILVA, Márcio. Narrar o trauma - A questão dos testemunhos de catástrofes históricas. Psicologia clínica, Rio de Janeiro, vol. 20, n. 1. Rio de Janeiro, 2008.

SELIGMANN-SILVA, Márcio. O local da diferença. São Paulo: Ed. 34, 2005.

SELIGMANN-SILVA, Márcio. O testemunho: entre a ficção e o "real". In: SELIGMANN-SILVA, Márcio (Org.). História, memória, literatura: o Testemunho na Era das Catástrofes. Campinas: Editora da UNICAMP, 2003d.

SELIGMANN-SILVA, Márcio. Os fragmentos de uma farsa. In: SELIGMANN-SILVA, Márcio (Org.). A literatura do trauma.Cult, n. 23, junho de 1999.

SPARKNOTES EDITORS. SparkNote on Poe's Short Stories. SparkNotes LLC. 2002. Disponível em: http://www.sparknotes.com/lit/poestories/. Acessado em 22 mar. 2010.

WILKOMIRSKI, Binjamin. Fragmentos: memórias de infância 1939-1948. Trad. Sérgio Tellaroli. São Paulo: Companhia das Letras, 1998. 